\title{
Effects of cutting frequency and height on alkaloid production in endophyte-infected drunken horse grass (Achnatherum inebrians)
}

\author{
ZHANG XingXu, LI ChunJie ${ }^{*}$ \& NAN ZhiBiao \\ State Key Laboratory of Grassland Agro-systems, College of Pastoral Agricultural Science and Technology, \\ Lanzhou University, Lanzhou 730020, China
}

Received March 30, 2011; accepted April 23, 2011

\begin{abstract}
An evaluation was performed on the influence of mowing height $(2.5,5.0$ or $7.5 \mathrm{~cm}$ ) and mowing frequency (weekly or fortnightly) on levels of ergot alkaloids (ergine and ergonovine) formed in drunken horse grass, Achnatherum inebrians, grown under greenhouse conditions. Samples were taken monthly and alkaloids were extracted and analyzed by reverse-phase HPLC. Alkaloid levels increased more or less linearly with plant age over the first four months following establishment. Levels were higher in samples cut fortnightly compared to those cut weekly, and were higher when plants were cut at a mowing height of $7.5 \mathrm{~cm}$ vs. $2.5 \mathrm{~cm}$. In most cases, the highest alkaloid levels observed were almost three times those of the lowest. If plant protection applications are developed for the endophytic fungus, Neotyphodium gansuense, it will be necessary to be aware of the potential role of plant husbandry practices (e.g., defoliation frequency and intensity) for reducing or enhancing levels of plant alkaloids. Similar husbandry factors may affect alkaloid levels in other Neotyphodium-grass associations, which would be interesting for further study.
\end{abstract}

Neotyphodium gansuense, Achnatherum inebrians, mowing height, mowing frequency, ergine, ergonovine

Citation: Zhang X X, Li C J, Nan Z B. Effects of cutting frequency and height on alkaloid production in endophyte-infected drunken horse grass (Achnatherum inebrians). Sci China Life Sci, 2011, 54: 567-571, doi: 10.1007/s11427-011-4181-y

Endophytic fungi belonging to the related genera Epichlö and Neotyphodium have been found in many cool-season grasses (subfamily Pooideae) [1,2]. Previous studies have focused mainly on the endophytes of Lolium and Festuca, because alkaloids produced in these associations are toxic to grazing animals [3-8].

Drunken horse grass (DHG, Achnatherum inebrians) is another endophyte-infected grass reported to be toxic to livestock. In China, DHG is mainly distributed throughout arid, semi-arid, alpine and subalpine native grasslands of Gansu, Xinjiang Uyghur Autonomous Region, Qinghai and Ningxia Hui Autonomous Region as well as Inner Mongolia and Tibet [9]. Toxicity symptoms are typically seen in livestock after grazing DHG when forage is in short supply,

*Corresponding author (email: chunjie@1zu.edu.cn) which are apparently caused by the endophyte Neotyphodium gansuense [10,11]. However, the $N$. gansuense endophyte provides DHG with a strong competitive ability due to an increased host tolerance to abiotic [11] and biotic [12-14] stresses. Endophyte-infected (E+) DHG has been shown to contain high levels of the ergot alkaloids, ergine and ergonovine [15,16].

A significant research need is better understanding of factors affecting alkaloid levels in grass-endophyte associations. In turf culture, there exists an interest in formulating husbandry practices that enhance alkaloid levels, as higher levels typically discourage predators [17-20]. By contrast, such information can be useful to pastoralists in the formulation of husbandry practices that minimize the exposure of grazing animals to these toxins. One point that has received comparatively little study is the finding described by 
Salminen and Grewal [21] and Salminen et al. [22] that an increase in defoliation frequency or intensity decreases the levels of some alkaloids produced by Neotyphodium lolii and Neotyphodium coenophialum in perennial ryegrass and tall fescue, respectively. The findings of these two studies might represent a general response of grass-endophyte associations. To test this hypothesis, the following experiments were performed using a different grass-endophyte association, DHG and N. gansuense, in China.

\section{Materials and methods}

To determine whether the effects of cutting height and frequency previously reported represent a more general phenomenon, we largely followed previous experimental methodology [21,22] with minor modification.

\subsection{Plant establishment}

DHG seeds were collected in September 2005 from endophyte-infected plants grown in the experimental area of the College of Pastoral Agricultural Science and Technology, Lanzhou University, Lanzhou, China. Pots $(30 \mathrm{~cm} \times 25 \mathrm{~cm} \times$ $8 \mathrm{~cm}$ ) were filled with silt loam soil sterilized in an oven at $160^{\circ} \mathrm{C}$ for $6 \mathrm{~h}$. Only well-filled, healthy-looking seeds were used. Five rows of 10 seeds were planted in each pot. Pots were placed in a constant temperature greenhouse $\left(22^{\circ} \mathrm{C}\right)$ with a day/night cycle of $16 \mathrm{~h}$ light/ $8 \mathrm{~h}$ dark, using artificial light, and were watered as required. Seedlings emerged approximately 3-4 d after planting. From approximately one month onward, plants were defoliated weekly to $5 \mathrm{~cm}$ above soil level.

\subsection{Cutting height}

At approximately six weeks from sowing, 36 pots (3 replicates $\times 3$ treatments $\times 4$ harvest dates) were randomly assigned to three cutting height treatments $(2.5,5.0$ or $7.5 \mathrm{~cm}$ above the soil surface). Plants were cut weekly to the designated height for one, two, three or four months. Nine pots in each time interval were destructively harvested by cutting to ground level approximately a quarter of the herbage in the center of the pot. These samples were immediately frozen in liquid nitrogen, lyophilized, ground to a powder and then stored for analysis.

\subsection{Cutting frequency}

To investigate effects of cutting frequency on alkaloid levels, 24 pots ( 3 replicates $\times 2$ treatments $\times 4$ harvest dates) were randomly assigned to two cutting treatments: Either plants were cut weekly, or once every two weeks. The cutting height was $5.0 \mathrm{~cm}$ above the soil surface. Sample collection from the center of each pot was carried out monthly, over four months, as described above.

\subsection{Alkaloid extraction}

The freeze-dried and ground grass material $(50 \mathrm{mg})$ was extracted in two stages using a two-phase solvent system, following a method modified from Miles et al. [15]. These samples were quantified on an Agilent $1100 \mathrm{HPLC}$, with an Agilent $250 \mathrm{~mm} \times 4.6 \mathrm{~mm} \mathrm{C}_{18}$ column containing $5 \mu \mathrm{L}$ particles. Mobile phases were "A" $\left(0.1 \mathrm{~mol} \mathrm{~L}^{-1} \mathrm{NH}_{4} \mathrm{OAc}\right)$ and "B" $\left(\mathrm{CH}_{3} \mathrm{CN}: 0.1 \mathrm{~mol} \mathrm{~L}^{-1} \mathrm{NH}_{4} \mathrm{OAc}, 3: 1\right)$ used at a flow rate of $1 \mathrm{~mL} \mathrm{~min}{ }^{-1}$. The elution scheme was $95 \%$ A (initial 10 $\mathrm{min}$ ), then ramped down over $10 \mathrm{~min}$ to $80 \% \mathrm{~A}$, then ramped down over $10 \mathrm{~min}$ to $50 \% \mathrm{~A}$, and finally ramped back up over 5 min to $95 \%$ A. A fixed-wavelength UV detector (G1314A VWD, Agilent) set at $312 \mathrm{~nm}$ was used to detect the alkaloids. Alkaloid levels in $20 \mu \mathrm{L}$ injection samples were quantified by comparing their peak areas with external standard curves. Ergonovine was purchased from Sigma-Aldrich China. The ergine used was a gift from Dr. Miroslav Flieger, Institute of Microbiology, Academy of Sciences of the Czech Republic, Prague, Czech Republic.

\subsection{Statistical analysis}

Variation in ergot alkaloid levels at different mowing heights and frequencies was analyzed using a factorial analysis of variance (ANOVA) procedure (SPSS 13.0, Chicago, IL, USA), using pots as experimental units. The ANOVA included a term for the treatment and time interactions.

\section{Results}

Results were consistent across replicates with small measurement errors compared to the size of treatment effects. This led to statistically significant results $(P<0.001)$ for both of the endophytic alkaloids and for all treatment effects and interactions for which $F$-tests were performed.

\subsection{Cutting height}

All effects of the repeated measures ANOVA are shown in Figure 1. Levels of ergonovine were significantly $(P<0.05)$ higher than levels of ergine in all parts of E+ DHG plants. In general, ergonovine levels were about double those of ergine. Levels of both alkaloids increased over the growing months and levels increased with plant age and with cutting height, in a nearly linear pattern.

The effects of plant cutting heights on ergine levels were significant $(P<0.05)$, although the difference between 2.5 and $5.0 \mathrm{~cm}$ was not significant $(P>0.05)$ at three months. All the results among months were also significant $(P<0.05)$. There was an interaction between plant age and defoliation 
height, in that the cutting height effect was smaller in plants at one month of age (Figure 1A).

The effects of cutting height on ergonovine levels were also significant $(P<0.05)$, although the difference between 2.5 and $5.0 \mathrm{~cm}$ was not significant $(P>0.05)$ after cutting at one month, and the difference between 5.0 and $7.5 \mathrm{~cm}$ was not significant $(P>0.05)$ at four months. All the results among months were also significant $(P<0.05)$ (Figure $1 \mathrm{~B})$.

\subsection{Cutting frequency}

The effects of cutting frequency closely paralleled those of cutting height, with initial levels of the two alkaloids being similar and increasing in a similar way with plant age. However, the rise in endophytic alkaloid levels was greater with less frequent defoliation than those with increased cutting height, with differences in levels between frequently and infrequently cut plants continuing to widen throughout the experiment.

The effects of cutting frequency and month of growth on ergine levels were significant $(P<0.05)$. There was significantly $(P<0.05)$ more ergine in plants cut weekly than those biweekly at two, three, and four months, with increases of $45.65 \%, 59.6 \%$ and $68.2 \%$, respectively (Figure $2 \mathrm{~A}$ ).
The effects of cutting frequency and month of growth on ergonovine levels were also significant $(P<0.05)$. There was significantly $(P<0.05)$ more ergonovine in plants cut weekly than those biweekly at two, three, and four months, with increases of $28.6 \%, 31.9 \%$ and $35.1 \%$, respectively (Figure 2B).

\section{Discussion}

The toxicity of DHG to Equus caballus, E. asinus and E. caballus $\times$ E. asinus has been reported by Dang et al. [23]. Miles et al. [15] reported that ergonovine and lysergic acid amide (i.e., ergine) were the major ergot alkaloids in DHG in Xinjiang Uyghur Autonomous Region. Li et al. [16] reported ergonovine and ergine levels and their temporal variation in Neotyphodium endophyte-infected (E+) and endophyte-free (E-) DHG grown in Gansu Province. Zhang and Chu [24] isolated ergonovine (25 $\mathrm{mg}$ from $2 \mathrm{~kg}$ ) and ergonovinine (30 mg from $7 \mathrm{~kg}$ ) from dry powdered DHG. Sang et al. [25] also detected seven alkaloids from DHG grown near the Jinqiang River, Gansu Province. The steps in ergot alkaloid biosynthesis by an endophyte of perennial ryegrass have been reported by Wang et al. [26].

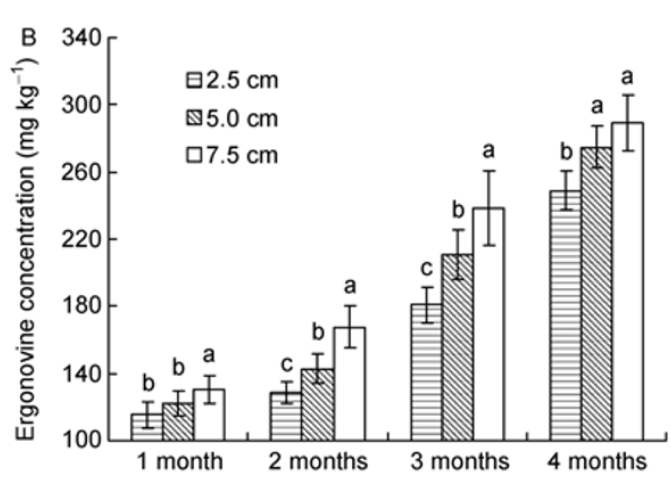

Figure 1 Effect of cutting weekly at different heights $(2.5,5.0$ or $7.5 \mathrm{~cm}$ ) on ergot alkaloids (A for ergine and B for ergonovine) concentrations in endophyte-infected drunken horse grass (Achnatherum inebrians). Values are means \pm standard error (SE) and bars indicate SE. Non-matching small letters indicate a significant difference $(P<0.05)$.
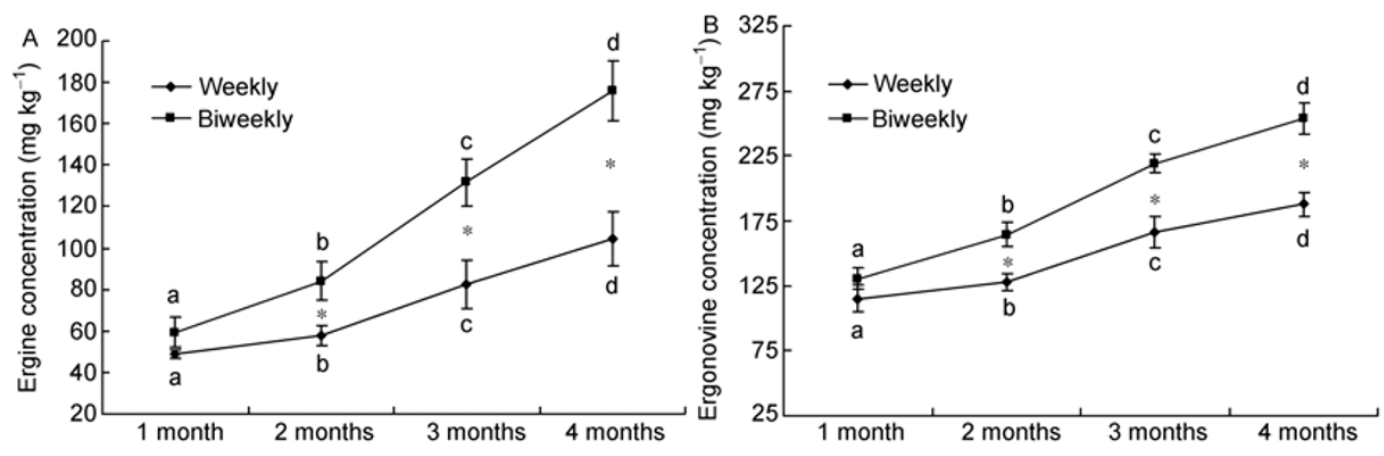

Figure 2 Effect of different cutting frequency (weekly or biweekly) on ergot alkaloids (A for ergine and B for ergonovine) concentrations in endophyte-infected drunken horse grass (Achnatherum inebrians). Values are means \pm standard error (SE) and bars indicate SE. * shows a significant difference $(P<0.05)$ between mowing frequencies. Non-matching small letters in the same line indicate significant difference $(P<0.05)$. 
It has been shown that alkaloid levels in both the leaf blades and seed ears were significantly $(P<0.05)$ higher than those in stems [16]. In accordance with the distribution of the endophyte in plant tissues, alkaloids were concentrated within the more terrestrial sections (rather than the aerial parts) of the plants. The same trend has been observed for peramine and Lolitrem B in infected perennial ryegrass, with the highest levels being in the crown near the soil; $75 \%$ of the alkaloids are found within $5 \mathrm{~cm}$ of the most basal parts, with the older leaves having higher alkaloid levels vs. young leaves [27-29]. By contrast, levels of ergot alkaloids have been reported highest in the seeds of infected tall fescue, significantly higher than in other plant parts [30-32].

Biweekly cutting has been shown to result in higher levels of ergovaline, ergonovine, and ergocristine in endophyte-infected tall fescue, with ergocristine and two putative alkaloids following a similar pattern in perennial ryegrass [21]. We found these same general patterns for ergine and ergonovine in DHG. It is clear that some alkaloids show a definite accumulation with increased mowing height in both tall fescue and perennial ryegrass [22]. Our research with DHG demonstrates a similar effect on the accumulation of ergot alkaloids.

It appears possible to influence the levels of endophytic alkaloids in DHG via mowing (e.g., frequency and height). Li et al. [13] demonstrated that endophytes can improve host resistance to the insect pests Rhopalosiphum padi and Tetranychus cinnabarinus. This type of resistance also occurs in many other turf grasses, and, as a consequence, some insect pests might be controlled through this mechanism [17-20]. Therefore, alkaloid enhancement in DHG could have important implications for pest management when this species is used as a turf grass.

However, DHG has excellent forage potential if alkaloid production can be inhibited or reduced, as its protein content can reach $15 \%$ [33]. Even with alkaloids present, livestock will graze this grass if winter forage is insufficient. Sward height is an important factor for animal grazing. Sheep, for example, exhibit a more consistent rate of grass intake when the tiller length is $7.7 \mathrm{~cm}(7.1 \mathrm{~g}$ dry matter $\left.\min ^{-1}\right)$ than when it is $3.7 \mathrm{~cm}\left(1.0 \mathrm{~g}\right.$ dry matter $\left.\min ^{-1}\right)$ [34]. Mowing this grass at a greater height also facilitates harvesting and storage. However, the present study demonstrates that DHG alkaloids are likely to increase under this treatment. This remains one of the main challenges in establishing this grass species as a significant forage crop.

We thank Prof. Cory Matthew and Dr. Peter Long for polishing the English and providing beneficial discussion of the experiment. This work was supported by the National Basic Research Program of China (Grant No. 2007CB108902), the National Natural Science Foundation of China (Grant No. 30771531), Program for New Century Excellent Talents in University (Grant No. NCET-08-0256) and the Fundamental Research Funds for the Central Universities (Grant No. LZUJBKY-2009-156).
1 White J F J, Morgan-Jones G. Endophyte-host associations in forage grass. X. Culture studies on some species of Acremonium sect albo-lanosa, including a new species, A. starrii. Mycotaxon, 1987, 30: 87-95

2 Schardl C L, Leuchtmann A. The Epichloë endophytes of grasses and the symbiotic continnuum. In: Dighton J, White J F, Oudemans P, eds. The Fungal Community. 3rd ed. Boca Raton: CRC Press, 2004. 475-503

3 Siegel M R, Latch G C M, Johnson M C. Acremonium fungal endophytes of tall fescue and perennial ryegrass-significance and control. Plant Dis, 1985, 69: 179-183

4 Prestidge R A, Gallagher R T. Acremonium endophytes in perennial ryegrass, ryegrass staggers in lambs, and growth rate of Argentine stem weevil larvae. In: Stahle P P, ed. Proceedings of the 5th Australasian Conference on Grassland Invertebrate Ecology, Melbourne, Australia, 1988. 229-235

5 Oliveira J A, Rottinghaus G E, Prego C. Endophytic fungi and alkaloid production in grass seeds in northern Spain. In: Proceedings of 4th International Neotyphodium/Grass Interactions Symposium, Soest, Germany, 2000. 413-417

6 Fletcher L R. Managing ryegrass-endophyte toxicoses. In: Roberts C A, West C P, Spiers D E, eds. Neotyphodium in Cool-season Grasses. Ames: Blackwell Publishing, 2005. 229-241

7 Bacon C W, Porter J K, Robbins J D, et al. Epichloë typhina from toxic tall fescue grasses. Appl Environ Microb, 1977, 34: 576-581

8 Fletcher L R, Harvey I C. An association of a Lolium endophytes with ryegrass staggers. New Zeal Vet J, 1981, 29: 185-186

9 Li C J, Nan Z B, Gao J H, et al. Detection and distribution of Neotyphodium-Achnatherum inebrians association in China. In: Proceedings of 5th International Neotyphodium/Grass Interactions Symposium, Arkansas, USA, 2004

10 Li C J, Nan Z B, Paul V H, et al. A new Neotyphodium species symbiotic with drunken horse grass (Achnatherum inebrians) in China. Mycotaxon, 2004b, 90: 141-147

11 Li C J, Nan Z B, Zhang C J, et al. Effects of endophyte infected drunken horse grass on Chinese rabbit. J Agr Sci Tech, 2009, 11: 90-96

12 Li C J, Nan Z B, Li F. Biological and physiological characteristics of Neotyphodium gansuense symbiotic with Achnatherum inebrians. Microbiol Res, 2007a, 163: 431-440

13 Li C J, Zhang X X, Li F, et al. Disease and pests resistance of endophyte infected and non-infected drunken horse grass. In: Popay A, Thom E R, eds. Proceedings of the 6th International Symposium on Fungal Endophytes of Grasses, Dunedin, New Zealand, 2007. 111-114

14 Zhang X X, Li C J. Effects on bird cherry-oat aphid resistance to drunken horse grass by Neotyphodium endophyte infection. In: Organizing Committee of 2008 IGC/IRC Conference, ed. Multifunctional Grasslands in a Changing World. Volume II. Guangzhou: Guangdong People's Publishing House, 2008. 833

15 Miles C O, Lane G A, Menna M E. High levels of ergonovine and lysergic acid amide in toxic Achnatherum inebrians accompany infection by an Acremonium like endophytic fungus. J Agr Food Chem, 1996, 5: 1285-1290

16 Li C J, Nan Z B, Schardl C L. Levels and temporal variation of ergot alkaloids in endophyte-infected drunken horse grass, Achnatherum inebrians, in China. In: APS, CPS and MSA Joint Meeting Abstracts, Quebec, Canada, 2006. 203-204

17 Clay K, Hardy T N, Hammond A M. Fungal endophytes of grasses and their effects on an insect herbivore. Oecologia, 1985, 66: 1-6

18 Goldbeter A, Dupont G. Allosteric regulation, cooperativity, and biochemical oscillations. Biophys Chem, 1990, 37: 341-353

19 Richmond D S, Niemczyk H K, Shetlar D J. Overseeding endophytic perennial ryegrass into stands of Kentucky bluegrass to manage bluegrass billbug (Coleoptera: Curculionidae). J Econ Entomol, 2000, 93: 1662-1668

20 Popay A J, Bonos S A. Biotic responses in endophytic grasses. In: Roberts C A, West C P, Spiers D E, eds. Neotyphodium in Cool-season Grasses. Ames: Blackwell Publishing, 2005. 163-185 
21 Salminen S O, Grewal P S. Does decreased mowing frequency enhance alkaloid production in endophytic tall fescue and perennial ryegrass? J Chem Ecol, 2002, 5: 939-950

22 Salminen S O, Grewal P S, Quigley M F. Does mowing height influence alkaloid production in endophytic tall fescue and perennial ryegrass? J Chem Ecol, 2003, 6: 1319-1328

23 Dang X P, Cao G R, Duan D X, et al. Studies on the toxic constituent of Achnatherum inebrians (in Chinese). Acta Vet Zootech Sin, 1992, 4: 366-371

24 Zhang Y, Chu T. Studies on the chemical compositions of Achnatherum inebrians. Chem J Chinese U, 1982, 3: 150-152

25 Sang M, Zhang J, Yao J, et al. Abstraction and analysis of poisonous components of Achnatherumn inebrians. Livestock Poultry Industry, 2006, 200: 9-11

26 Wang J H, Machado C, Panaccione D G, et al. The determinant step in ergot alkaloid biosynthesis by an endophyte of perennial ryegrass. Fungal Genet Biol, 2004, 41: 189-198

27 Dimenna M E, Mortimer P H, Prestidge R A. Lolitrem B concentrations, counts of Acremonium lolii hyphae, and the incidence of ryegrass staggers in lambs on plots of $A$. lolii-infected perennial ryegrass.
New Zeal J Agr Res, 1992, 35: 221-217

28 Ball O J P, Barker G M, Prestidge R A, et al. Distribution and accumulation of the mycotoxin lotitrem B in Neotyphodium lolii-infected perennial ryegrass. J Chem Ecol, 1997, 23: 1419-1434

29 Belesky D P, Hill N S. Defoliation and leaf age influence on ergot alkaloids in tall fescue. Ann Bot, 1997, 79: 259-264

30 White J F, Morgen-Jones G, Morrow A C. Taxonomy, life cycle, reproduction and detection of Acremonium endophytes. Agr Ecosyst Environ, 1993, 44: 13-37

31 Gentry C E, Chapman R A, Henson L. Factors affecting the alkaloid content of tall fescue (Festuca arundim acea Schreb). Agron J, 1969, 61: 313-316

32 Siegel M R, Latch G C, Johnson M C. Fungal endophytes of grasses. Annu Rev Phytopathol, 1987, 25: 293-315

33 Jia N T, Hela D H, Nu E L. Study on feed experiment of drunken horse grass (Achnatherum inebrians) (in Chinese). J Xinjiang Stock, 1998, 4: 31

34 Allden W G, Whittaker I A. The determinants of herbage intake by grazing sheep: The interrelationship of factors influencing herbage intake and availability. Aust J Arg Res, 1970, 5: 755-766

Open Access This article is distributed under the terms of the Creative Commons Attribution License which permits any use, distribution, and reproduction in any medium, provided the original author(s) and source are credited. 